\title{
Age-related variations in flavonoid intake and sources in the Australian population
}

\author{
Lidwine Johannot and Shawn M Somerset* \\ School of Public Health and Heart Foundation Research Centre, Griffith University, \\ University Drive, Meadowbrook, Queensland 4131, Australia
}

Submitted 9 November 2004: Accepted 27 July 2005

\begin{abstract}
Objective: To estimate flavonoid intake in the Australian population. Design: Flavonoid consumption was estimated from 24-hour recall data and apparent consumption data using US Department of Agriculture flavonoid composition data. Subjects: The National Nutrition Survey 1995 assessed dietary intake (24-hour recall) in a representative sample $(n=13858)$ of the Australian population aged 2 years and over.

Results: Analysis of the 24-hour recall data indicated an average adult intake $(>18$ years) of $454 \mathrm{mg} \mathrm{day}^{-1}$ ( $92 \%$ being flavan-3-ols). Apple was the highest quercetin source until age 16-18 years, after which onion became an increasingly important prominent source. Variations in hesperetin consumption reflected orange intake. Apple, apricot and grapes were the major sources of epicatechin and catechin for children, but subsided as wine consumption increased in adulthood. Wine was the main source of malvidin. Naringenin intake remained static as a percentage of total flavonoid intake until age 19-24 years, corresponding to orange intake, and then increased with age from 19-24 years, corresponding to grapefruit intake. Apparent dietary flavonoid consumption was $351 \mathrm{mg}$ person $^{-1}$ day $^{-1}$, of which $75 \%$ were flavan-3-ols. Black tea was the major flavonoid source (predominantly flavan-3-ols) representing $70 \%$ of total intake. Hesperetin and naringenin were the next most highly consumed flavonoids, reflecting orange intake. Both 24-hour recall and apparent consumption data indicated that apigenin intake was markedly higher in Australia than reported in either the USA or Denmark, presumably due to differences in consumption data for leaf and stalk vegetables and parsley.

Conclusions: Tea was the major dietary flavonoid source in Australia. Flavonoid consumption profiles and flavonoid sources varied according to age. More consistent methodologies, survey tools validated for specific flavonoid intakes and enhanced local flavonoid content data for foods would facilitate better international comparisons of flavonoid intake.
\end{abstract}

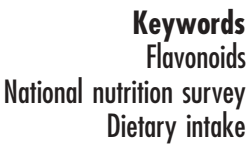

Keywords

ition survey Dietary intake
Flavonoids are a subclass of polyphenolic compounds found ubiquitously in plant foods. Their secondary metabolites have roles in processes such as pigmentation, defence immune responses and protection from ultraviolet-B radiation $^{1,2}$. More than 5000 identified flavonoids occur in plants ${ }^{3}$ and are divided into six major classes: anthocyanidins, flavan-3-ols, flavanones, flavones, flavonols and isoflavones ${ }^{3,4}$.

In vitro and in vivo studies indicate that dietary flavonoids affect the risk of various diseases including cancer and coronary heart disease (CHD). Population studies have shown associations between flavonoid consumption and CHD risk $^{5-7}$. At the molecular level, flavonoids may contribute to $\mathrm{CHD}$ risk reduction by affecting low-density lipoprotein (LDL) oxidation ${ }^{8,9}$, fatty plaques $^{10,11}$ and hypercholesterolaemia ${ }^{4,7}$. Moreover, they can inhibit the formation of reactive oxygen species and protect genes that decrease cancer risk ${ }^{12,13}$. In addition to antioxidant properties, some flavonoids exhibit antimicrobial, antiviral ${ }^{14}$, erythrocyte protection $^{15}$, antiinflammatory and antiallergenic properties ${ }^{16}$.

Given the potential role of flavonoids in disease prevention, it is useful to understand variations in consumption patterns. To date, few consumption studies have been published. One early study estimated the mean intake of total flavonoids in the USA to be about $1 \mathrm{~g}$ daily ${ }^{17}$. More recent studies have estimated individual flavonoid or flavonoid profile intakes in the $\mathrm{USA}^{18}$, Denmark ${ }^{19}$,

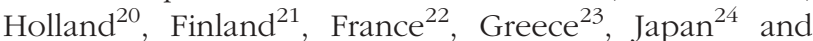
Spain $^{25}$, although the dietary intake methodologies vary substantially. The present study was initiated to add an Australian perspective to international comparisons. 
Further, major contributors to dietary flavonoid intake such as wine and tea vary in consumption across age groups ${ }^{26}$. The study sought to provide insight into how sources and intakes of various flavonoids vary according to age.

\section{Methods}

Data from two sources were used to formulate estimates of flavonoid intake. First, intake of flavonoids was derived from the most recent survey of dietary intake in Australia (the National Nutrition Survey 1995; NNS95) ${ }^{26}$. This survey used a nationally representative sub-sample $(n=17326)$ of the National Health Survey. People over the age of 2 years were included in the survey and the overall response rate was $80 \%$. It was based on a 24-hour recall of food and beverage intake on the day prior to the interview, midnight to midnight. This survey collected detailed descriptions on types and quantities of all foods and beverages consumed by respondents. Standardised measuring guides were used to assist respondents in estimating the amount of food actually consumed.

In the published NNS95 analysis, vegetables and fruits were grouped together. Therefore, the original dataset was reassessed by the Australian Bureau of Statistics (ABS) to provide intake data of consumption of individual flavonoid-containing foods (including mixed dishes), according to age grouping, based on the 24 hour-recall data. The following categories were ungrouped into individual foods: pome, berry, citrus, stone, tropical fruit, other fruits, cabbage, cauliflower and similar brassica vegetables, carrot and similar root vegetables, peas and beans, leaf and stalk vegetables, other fruiting vegetables, other vegetables and legumes.

To provide another perspective on flavonoid consumption, apparent consumption (per capita, all ages) of major dietary flavonoid sources was derived from agricultural production data ${ }^{27}$. In certain instances, single foods are grouped into categories within this agricultural dataset. For example, lettuce and celery are grouped into the category of leaf and green vegetables but have very different flavonoid profiles ${ }^{28}$. Therefore, industry production data sources were used in such cases to estimate the proportion of individual foods within the various ABS agricultural categories.

Since there is no comprehensive composition dataset for flavonoid contents of Australian foods, US Department of Agriculture (USDA) data were applied ${ }^{28}$, an approach that has been used in similar studies in other countries ${ }^{18,23}$. This currently is the most complete database available, with 225 reference foods. It should be noted that the USDA database has collated data from a range of sources, with variations in data quality ${ }^{28}$.

Table 1 Flavonoid intake $\left(\mathrm{mg} \mathrm{day}^{-1}\right)$ according to age, based on 24-hour recall data from the Australian National Nutrition Survey 1995

\begin{tabular}{|c|c|c|c|c|c|c|c|c|c|c|}
\hline & \multicolumn{10}{|c|}{ Age (years) } \\
\hline & $2-3$ & $4-7$ & $8-11$ & $12-15$ & $16-18$ & $19-24$ & $25-44$ & $45-64$ & $65+$ & $19+$ \\
\hline \multicolumn{11}{|l|}{ Anthocyanidins } \\
\hline Cyanidin & 0.00 & 0.67 & 0.56 & 0.00 & 0.02 & 0.03 & 0.35 & 0.56 & 0.96 & 0.42 \\
\hline Delphinidin & 0.00 & 0.00 & 0.00 & 0.00 & 0.05 & 0.07 & 0.21 & 0.27 & 0.17 & 0.21 \\
\hline Malvidin & 0.00 & 0.00 & 0.00 & 0.00 & 0.42 & 0.59 & 1.57 & 2.12 & 1.27 & 1.56 \\
\hline Pelargonidin & 0.00 & 0.01 & 0.00 & 0.00 & 0.00 & 0.00 & 0.01 & 0.00 & 0.01 & 0.00 \\
\hline Peonidin & 0.00 & 0.03 & 0.03 & 0.00 & 0.09 & 0.12 & 0.33 & 0.45 & 0.30 & 0.33 \\
\hline Petunidin & 0.00 & 0.00 & 0.00 & 0.00 & 0.10 & 0.14 & 0.38 & 0.51 & 0.31 & 0.38 \\
\hline \multicolumn{11}{|l|}{ Flavan-3-ols } \\
\hline Catechin & 1.42 & 1.24 & 1.35 & 1.68 & 2.20 & 3.77 & 8.00 & 12.09 & 12.53 & 9.36 \\
\hline Epicatechin & 4.92 & 5.43 & 5.44 & 6.44 & 5.23 & 7.38 & 14.10 & 20.87 & 23.14 & 16.64 \\
\hline Epicatechin-3-gallate & 0.92 & 1.06 & 1.99 & 2.94 & 4.14 & 13.37 & 27.00 & 43.54 & 53.09 & 34.21 \\
\hline Epigallocatechin & 1.16 & 1.39 & 2.66 & 3.91 & 5.64 & 18.29 & 36.95 & 59.60 & 72.74 & 46.84 \\
\hline Epigallocatechin-3-gallate & 1.89 & 2.25 & 4.33 & 6.36 & 9.16 & 29.74 & 60.07 & 96.92 & 118.28 & 76.17 \\
\hline Gallocatechin & 0.11 & 0.13 & 0.26 & 0.38 & 0.54 & 1.77 & 3.57 & 5.76 & 7.03 & 4.53 \\
\hline Theaflavin & 0.14 & 0.17 & 0.32 & 0.47 & 0.68 & 2.22 & 4.49 & 7.24 & 8.84 & 5.69 \\
\hline Theaflavin-3-gallate & 0.11 & 0.13 & 0.24 & 0.36 & 0.51 & 1.67 & 3.37 & 5.43 & 6.63 & 4.27 \\
\hline Theaflavin-3'-gallate & 0.14 & 0.17 & 0.32 & 0.47 & 0.67 & 2.18 & 4.41 & 7.12 & 8.69 & 5.60 \\
\hline Theaflavin-3,3'-digallate & 0.15 & 0.18 & 0.35 & 0.51 & 0.74 & 2.40 & 4.84 & 7.81 & 9.53 & 6.14 \\
\hline Thearubigins & 5.29 & 6.30 & 12.12 & 17.78 & 25.63 & 83.19 & 168.03 & 271.08 & 330.83 & 213.04 \\
\hline \multicolumn{11}{|l|}{ Flavanones } \\
\hline Eriodictyol & 0.00 & 0.00 & 0.00 & 0.00 & 0.00 & 0.00 & 0.00 & 0.02 & 0.04 & 0.02 \\
\hline Hesperetin & 3.74 & 4.46 & 4.43 & 4.35 & 3.73 & 2.97 & 4.14 & 5.89 & 5.71 & 4.75 \\
\hline Naringenin & 1.07 & 1.32 & 1.37 & 1.37 & 1.11 & 0.92 & 1.60 & 2.79 & 3.48 & 2.17 \\
\hline \multicolumn{11}{|l|}{ Flavones } \\
\hline Apigenin & 0.02 & 0.05 & 0.12 & 0.09 & 0.08 & 0.12 & 0.13 & 0.47 & 0.48 & 0.45 \\
\hline Luteolin & 0.01 & 0.02 & 0.04 & 0.03 & 0.04 & 0.05 & 0.07 & 0.09 & 0.10 & 0.08 \\
\hline \multicolumn{11}{|l|}{ Flavonols } \\
\hline Isorhamnetin & 0.05 & 0.03 & 0.05 & 0.06 & 0.14 & 0.14 & 0.16 & 0.18 & 0.18 & 0.16 \\
\hline Kaempferol & 0.24 & 0.30 & 0.49 & 0.69 & 0.94 & 2.43 & 4.49 & 7.05 & 8.47 & 5.60 \\
\hline Myricetin & 0.07 & 0.07 & 0.13 & 0.20 & 0.40 & 1.02 & 2.07 & 3.03 & 3.28 & 2.40 \\
\hline Quercetin & 2.87 & 3.33 & 3.63 & 4.48 & 4.47 & 6.45 & 10.80 & 15.30 & 17.03 & 12.53 \\
\hline
\end{tabular}


Table 2 Flavonoid intake $\left(\mathrm{mgday}^{-1}\right)$ reported in various studies, including reanalysis (using all flavonoids in Table 1) according to reported consumption of foods

\begin{tabular}{|c|c|c|}
\hline Country (reference) & Published flavonoid consumption & Reanalysis \\
\hline $\begin{array}{l}\text { National representative sa } \\
\text { Australia (present study) }\end{array}$ & & $\begin{array}{l}\text { National Nutrition Survey, } 24 \text {-hour recall: } \\
\text { - Anthocyanidins: } 2.9 \\
\text { - Flavan-3-ols: } 422 \\
\text { - Flavanones: } 6.9 \\
\text { - Flavones: } 0.5 \\
\text { - Flavonols: } 20.7 \\
\text { Total: } 454\end{array}$ \\
\hline Denmark $^{19}$ & $\begin{array}{l}\text { Danish Household Consumption Survey (dietary history): } \\
\text { - Flavanones (hesperetin, naringenin): } 9 \\
\text { - Flavonols (quercetin, kaempferol, myricetin): } 16.8 \\
\text { Total: } 25.8\end{array}$ & $\begin{array}{l}\text { Analysis of reported food intake: } \\
\text { - Anthocyanidins: } 1.2 \\
\text { - Flavan-3-ols: } 148 \\
\text { - Flavanones: } 12.4 \\
\text { - Flavones: } 0 \\
\text { - Flavonols: } 12.4 \\
\text { Total: } 175\end{array}$ \\
\hline $\begin{array}{l}\text { The Netherlands } \\
\left(n=4112^{20} ; n=6200^{29}\right) \\
\text { USA }^{18}\end{array}$ & $\begin{array}{l}\text { Dutch National Food Consumption Survey (dietary history): } \\
\text { - Flavan-3-ols (catechin): } 50 \\
\text { - Flavones (apigenin, luteolin): } 1.6 \\
\text { Total: } 73.0 \\
\text { US health professionals (FFQ, } n=116772 \text { ): } \\
\text { Total: } 21.7\end{array}$ & $\begin{array}{l}\text { Analysis of reported food intake: } \\
\text { - Anthocyanidins: } 13.8 \\
\text { - Flavan-3-ols: } 145 \\
\text { - Flavanones: } 32 \\
\text { - Flavones: } 0.06 \\
\text { - Flavonols: } 20.7 \\
\text { Total: } 211\end{array}$ \\
\hline $\begin{array}{l}\text { Non representative sub-sa } \\
\text { Australia }^{30}\end{array}$ & $\begin{array}{l}\text { Healthy young women with dietary data }(n=24) \text { : } \\
\text { - Flavan-3-ols (epicatechin, epicatechin-3-gallate, } \\
\text { epigallocatechin, epigallocatechin-3-gallate, catechin, } \\
\text { gallocatechin): } 76.1 \\
\text { - Flavanones (eriodictyol, hesperetin, naringenin): } 22.6 \\
\text { - Flavones (apigenin, luteolin): } 3.9 \\
\text { - Flavonols (quercetin, kaempferol, myricetin, fisetin): } 25.6 \\
\text { Total: } 128.2\end{array}$ & \\
\hline Finland $^{31}$ & $\begin{array}{l}\text { Finnish Mobile Clinic Health Examination Survey } \\
(n=10054 \text { subset, dietary history): } \\
\text { - Flavanones (hesperetin, naringenin): } 20.2 \\
\text { - Flavonols (kaempferol, myricetin, quercetin): } 4.0 \\
\text { Total: } 24.2\end{array}$ & \\
\hline France $^{22}$ & $\begin{array}{l}\text { Subjects above } 65 \text { years of age }(n=1367) \text { : } \\
\text { - Flavones (apigenin, luteolin) } \\
\text { - Flavonols (quercetin, kaempferol, myricetin) } \\
\text { Total: } 14.4 \text { (no individual values given) }\end{array}$ & \\
\hline Greece $^{23}$ & $\begin{array}{l}\text { Greeks }(n=210) \text { including } 110 \text { with stomach } \\
\text { adenocarcinoma (FFQ): } \\
\text { - Anthocyanidins: } 40.4 \\
\text { - Flavan-3-ols: } 135 \\
\text { - Flavanones: } 19.8 \\
\text { - Flavones: } 0.3 \\
\text { - Flavonols: } 10 \\
\text { Toflavones: } 2.0 \\
\text { Total: } 207.6 \text { (no details of individual flavonoids given) }\end{array}$ & \\
\hline Japan $^{24}$ & $\begin{array}{l}\text { Women ( } n=115,3 \text {-day dietary history): } \\
\text { - Flavones (luteolin): } 0.3 \\
\text { - Flavonols (quercetin, kaempferol, myricetin): } 16.4 \\
\text { Isoflavones (daidzein, genistein): } 47.2 \\
\text { Total: } 64\end{array}$ & \\
\hline Spain $^{25}$ & $\begin{array}{l}\text { Spanish gastric adenocarcinoma patients }(n=354) \text { : } \\
\text { - Flavonols (quercetin, kaempferol, myricetin): } 9.0 \\
\text { Total: } 9.0\end{array}$ & \\
\hline
\end{tabular}

FFQ - food-frequency questionnaire. 
Previous studies from Denmark, The Netherlands and the USA published dietary data in conjunction with estimates of flavonoid intake. The dietary data from such studies were reanalysed for all flavonoids listed in Table 1, applying USDA food composition data, to derive the reanalysed totals in Table 2. The Statistical Package for the Social Sciences (SPSS version 12.0.1; SPSS Inc., Chicago, IL, USA) was used to derive mean intake values.

\section{Results}

Dietary flavonoid intake from NNS95 data was estimated at $225 \mathrm{mg}$ person ${ }^{-1}$ day $^{-1}$ (only 145 of the 225 USDA reference foods were reported to be consumed). Consumption of individual flavonoids in each age group is shown in Table 1. People aged 19 years and over consumed $454 \mathrm{mg} \mathrm{day}^{-1}$, of which $92 \%$ were flavan-3-ols (Fig. 1). This difference between all ages and adult people was due predominantly to tea consumption, which increased with age starting at 19-24 years (see Fig. 6 below). The average Australian apparent flavonoid consumption was $351 \mathrm{mg} \mathrm{day}^{-1}$ of which $75 \%$ were flavan-3-ols (Fig. 1). Apart from tea which contributed $76 \%$ of flavonoid intake, the highest flavonoid source was oranges - supplying four times more flavonoids than any other fruit, beverage or vegetable group. Other important flavonoid sources were, in descending order, other citrus fruit, grapes, wine, apples and leaf and stalk vegetables.

In the NNS95 analysis, black tea was the major flavonoid source (predominantly flavan-3-ols). Figure 2 shows proportions of non-flavan-3-ol flavonoid classes determined by the two intake assessment methods. Because of the dominance of flavan-3-ols in total flavonoid intake, the data from NNS95 were analysed in the absence of contributions from black and green tea (Fig. 3). This enabled a clearer visualisation of the intake dynamics of flavonoids other than those supplied exclusively by black and green tea.

The range of individual flavonoids included in previous consumption studies is relatively varied and comparisons are therefore limited in their scope. Figure 4 compares the consumption estimates for five major flavonoids from previous studies with those of the present study. Quercetin dominated flavonoid intake profiles for all four countries (Fig. 4) even when tea consumption was not considered (Fig. 5).

Apart from tea flavonoids, hesperetin and naringenin consumption was high, in view of citrus fruit intake (especially oranges). Tea was not the sole source of catechin, epicatechin and quercetin, which were still important contributors to total flavonoid consumption (via wine) for adults and apples for all ages. Although these five flavonoids were the major dietary flavonoids across all ages in the present study, variations in consumption of individual flavonoids occurred according to age (Figs 6-10). Analysis of 24 hour-recall data from the NNS95 revealed apple as the most important source of quercetin until age $16-18$ years, after which onions became an increasingly important prominent source. Variations in hesperetin consumption reflected orange intake. Apple was also the major source of epicatechin and catechin for children. For catechin, grapes and peach also contributed. However, these sources became less prominent as wine consumption increased in adulthood. Wine was the predominant source of malvidin, as well as delphinidin, peonidin and petunidin which all followed wine consumption patterns. Variations in hesperetin consumption reflected orange intake. Naringenin intake was consistent as a percentage of total flavonoid intake until 19-24 years, corresponding to orange intake. Naringenin intake then increased with age corresponding to grapefruit intake.

\section{Discussion}

The use of US flavonoid content data in the analysis of Australian dietary data is not ideal, and was done in the absence of adequate local data. The USDA acknowledges that factors such as cultivar, geography, climate, farming practices, processing and storage can introduce substantial variation in flavonoid content of foods ${ }^{28}$. The extent to which flavonoid intake estimates in this study would vary if local composition data were available is not known.

The consumption of flavan-3-ol dominated the flavonoid intake profile determined by both methods in this study, similar to consumption data for national flavonoid intakes for Denmark and the USA (Fig. 1). This is due to the importance of black tea in the diet of these countries. The reported average total flavonoid consumption for Denmark is markedly lower than the Australian and US estimates (175 vs. 454 and $211 \mathrm{mg} \mathrm{day}^{-1}$, respectively), due to variations in single flavonoid intakes between countries (Table 2). In the USA, flavan-3-ols represented only $68 \%$ of total flavonoid consumption due to lower tea consumption.

The second most abundant class of flavonoids in the US diet are flavanones (15\% of total flavonoids). In Denmark and the present 24-hour recall analysis, flavanones represent a smaller proportion because of the dominance of flavan-3-ols from black tea (Fig. 1). When tea consumption was excluded, variations in flavanone proportions were still apparent (Fig. 3). Anthocyanidin consumption was higher in the USA than in other countries, probably due to higher consumption of blueberries which are a very rich source ${ }^{28}$. However, the Danish analysis only included blackcurrant and not other major anthocyanidin sources such as cherries and berries, and may therefore be an underestimate of true consumption. The consumption of flavones in Australia was higher than that reported for Denmark and USA, due to celery and parsley consumption not being analysed in the Danish and US studies. Comparisons of flavonoid intake from various countries are shown in Table 2 . These combined 
Australia (NNS95 24-hour recall)

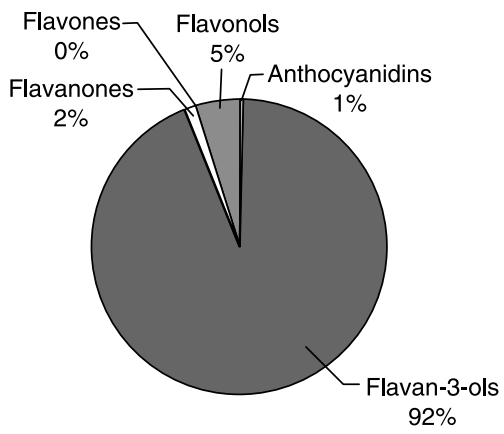

Australia (apparent consumption)

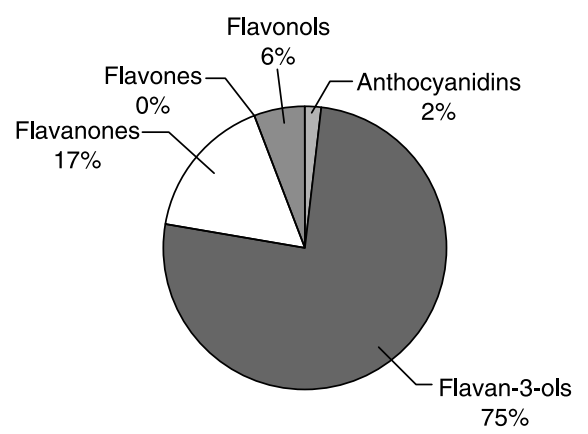

Denmark

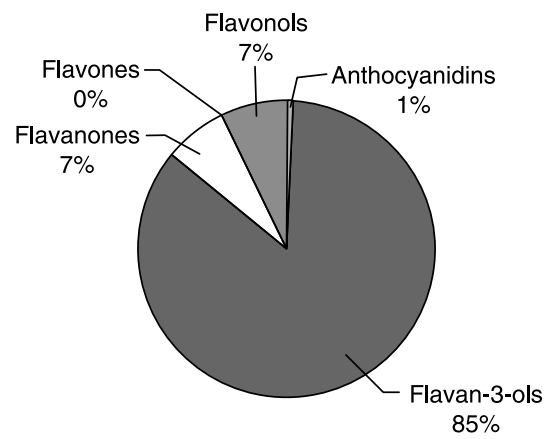

United States

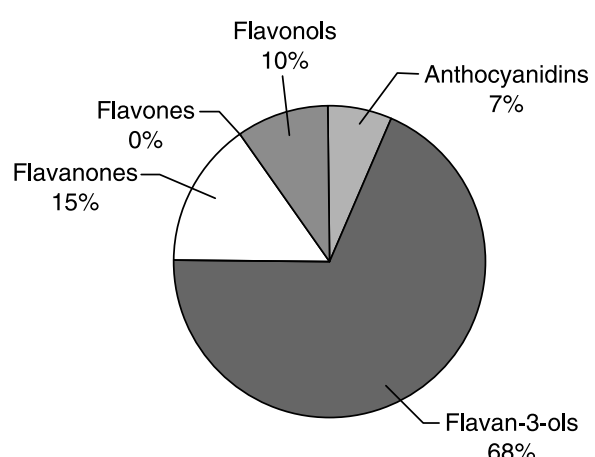

Fig. 1 Intakes (proportions) of flavonoid classes reported in the USA ${ }^{18}$ and Denmark ${ }^{19}$ compared with Australian estimates (24-hour recall data from the National Nutrition Survey 1995 (NNS95) and apparent consumption data) from the present study

Australia (NNS95 24-hour recall)

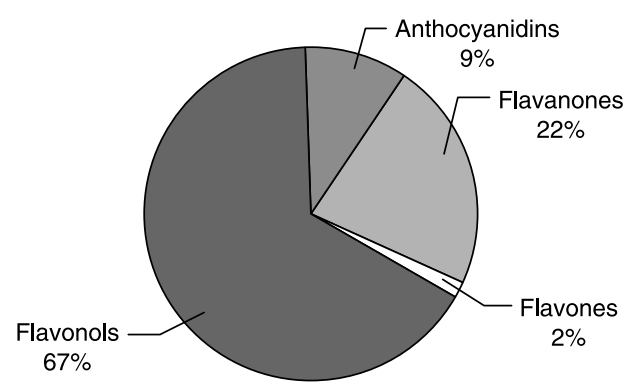

Australia (apparent consumption)

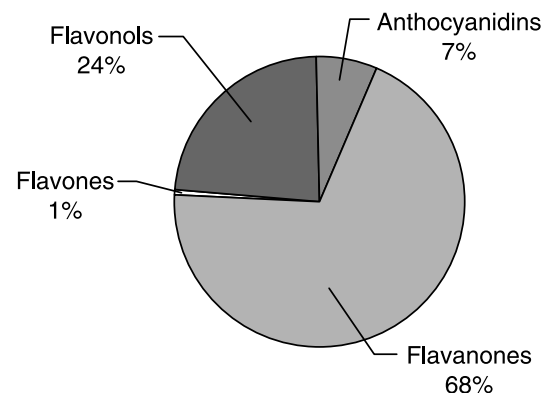

Denmark

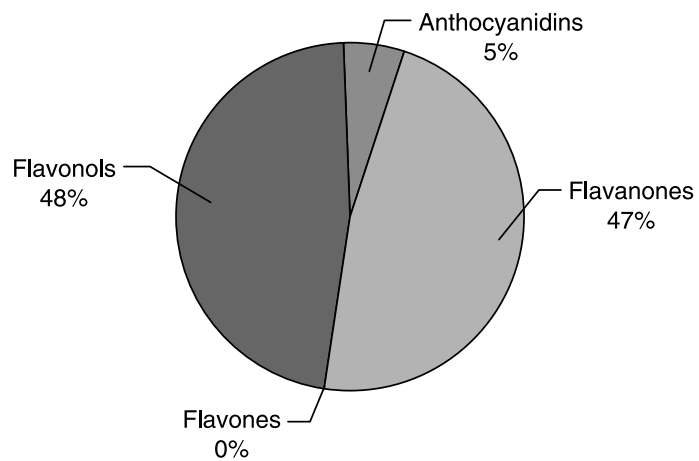

United States

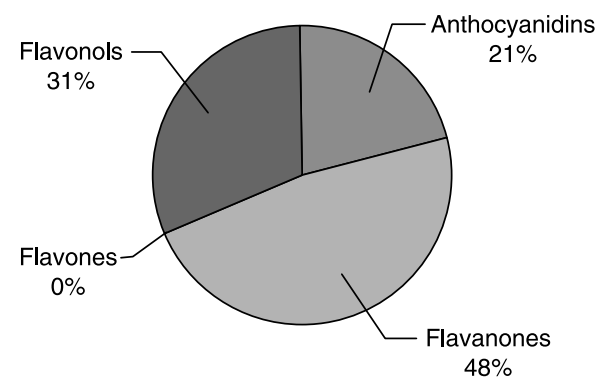

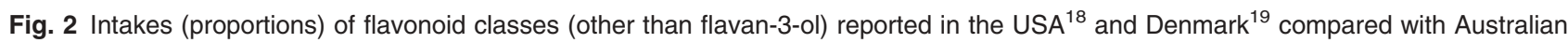
estimates (24-hour recall data from the National Nutrition Survey 1995 (NNS95) and apparent consumption data) from the present study 
Australia (NNS95 24-hour recall)

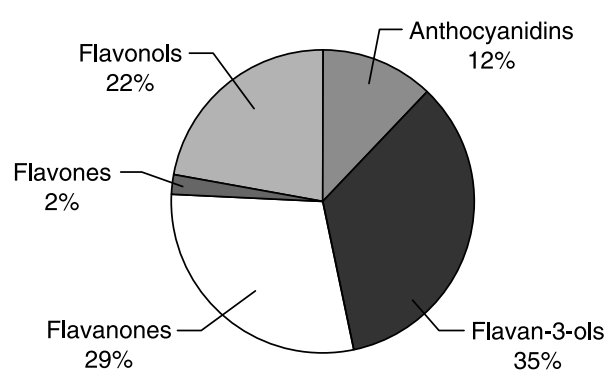

Australia (apparent consumption)

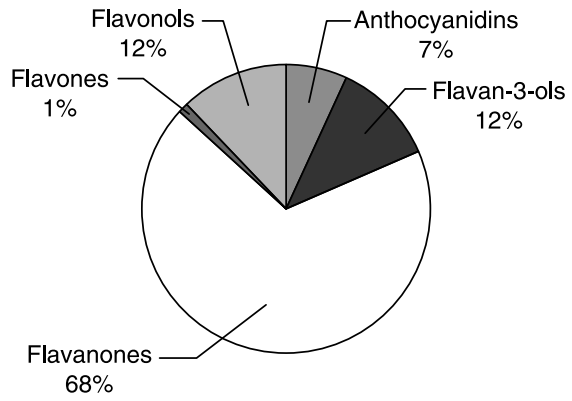

L Johannot and SM Somerset

Denmark

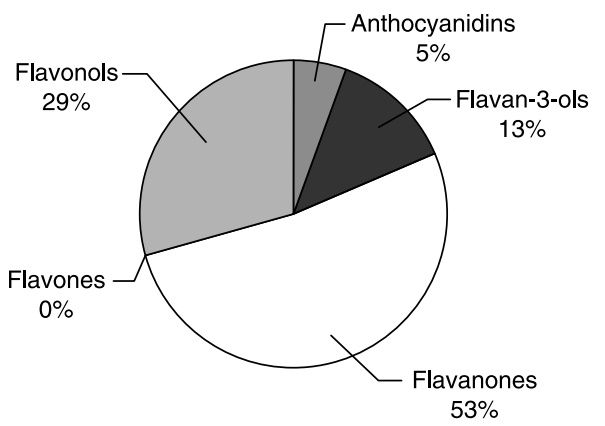

United States

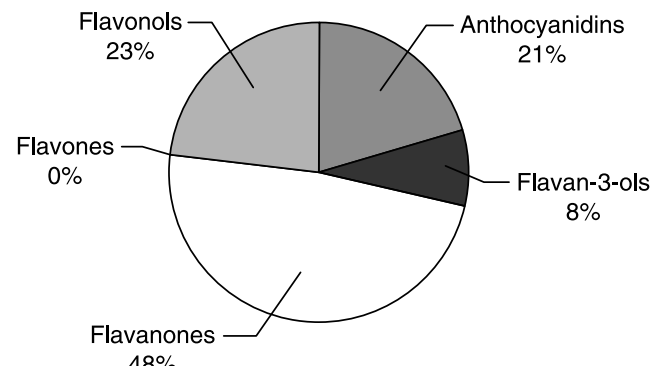

Fig. 3 Intakes (proportions) of flavonoid classes reported in the USA ${ }^{19}$ and Denmark ${ }^{18}$ compared with Australian estimates (24-hour recall data from the National Nutrition Survey 1995 (NNS95) and apparent consumption data) from the present study (excluding tea consumption)

data indicate that such dietary studies vary in their methodological approaches. In view of the number of dietary flavonoid sources and the extensive range of flavonoids found in foods, diet diary methods offer more reliable flavonoid intake data than food-frequency questionnaires, since the latter often have not been validated for flavonoid intake and individual flavonoid sources can easily be overlooked.
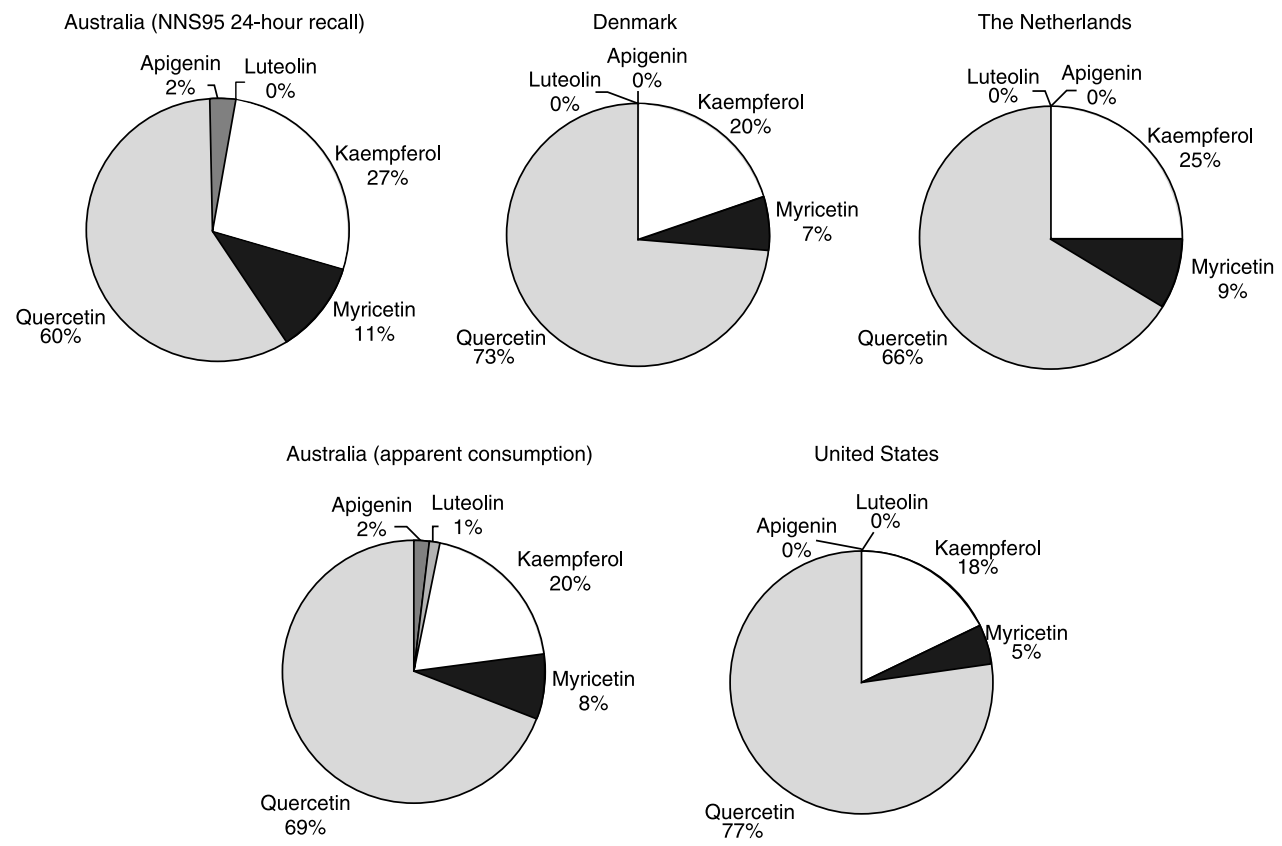

Fig. 4 Intakes of individual flavonols and flavones (percentage of total flavonoid intake) reported in the USA ${ }^{18}$, Denmark ${ }^{19}$ and The Netherlands ${ }^{20,32}$ compared with Australian estimates (24-hour recall data from the National Nutrition Survey 1995 (NNS95) and apparent consumption data) from the present study (including tea consumption) 

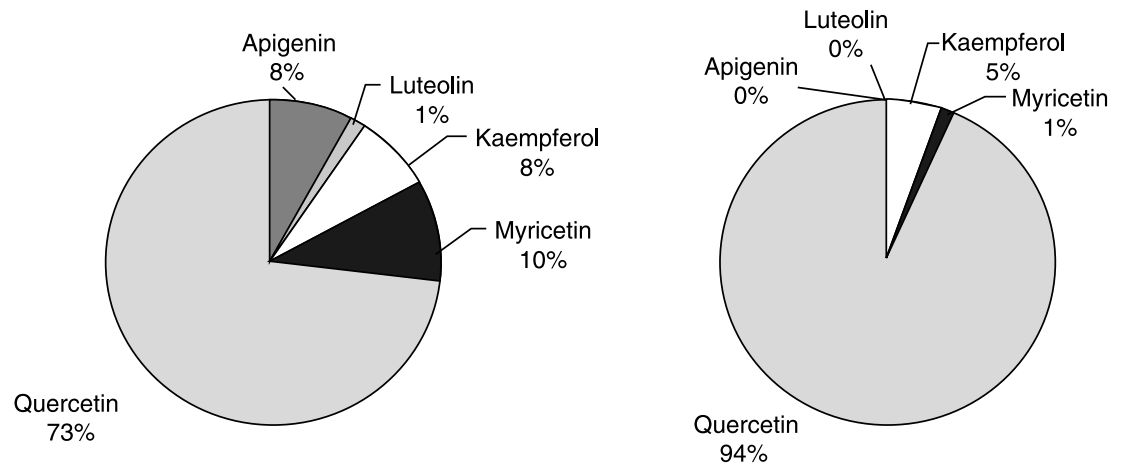

Australia (apparent consumption)

United States

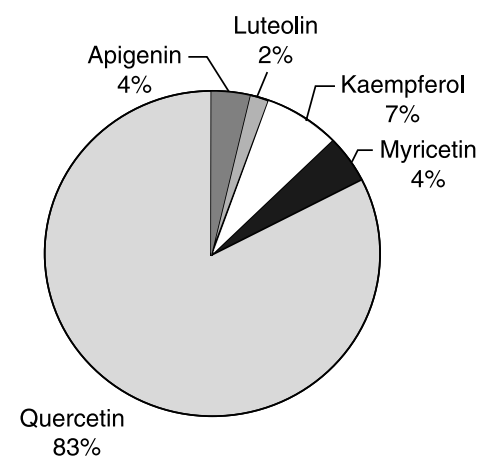

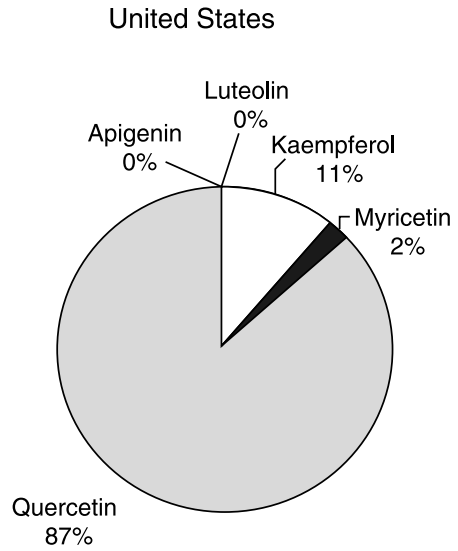

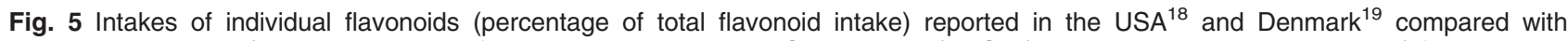
Australian estimates (24-hour recall data from the National Nutrition Survey 1995 (NNS95) and apparent consumption data) from the present study (excluding tea consumption)

Figure 3 revealed a higher flavan-3-ol consumption in Australia than the comparison countries due to the inclusion of both wine and apple (vs. apple only) in the present study. Figure 4 highlights the lack of methodological consistency between studies outlined in Table 2. Apiengenin consumption appears higher in Australia, but is due to parsley and celery consumption not being included in other studies. The apparent greater diversities of flavonoid consumption in Australia compared with Denmark and the USA is likely due

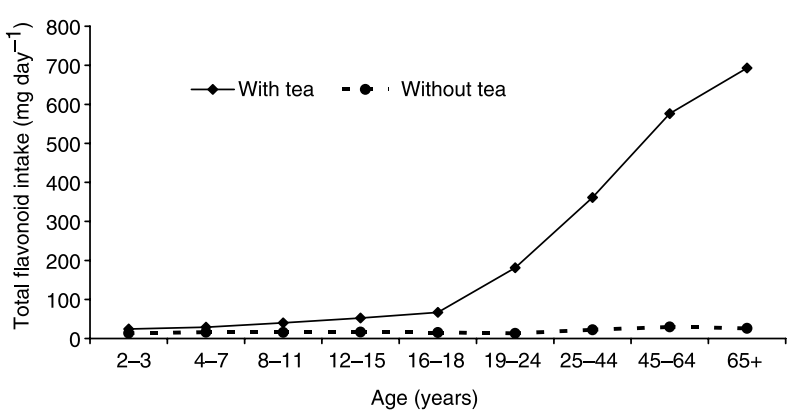

Fig. 6 Comparison of total flavonoid intake $\left(\mathrm{mgday}^{-1}\right)$, with or without tea, according to age group; 24-hour recall data from the Australian National Nutrition Survey 1995 to the broader range of flavonoid-rich foods included the present study. In Table 2, estimates were reanalysed using food intakes reported in the original studies. Reanalysis of the Dutch study was not done because consumption of individual foods was not reported.

Estimates of flavonoid consumption in various countries have used non-representative sub-samples of national populations. An Australian study of 24 women reported total flavonoid intake of $128 \mathrm{mg} \mathrm{day}^{-1}$, with intake

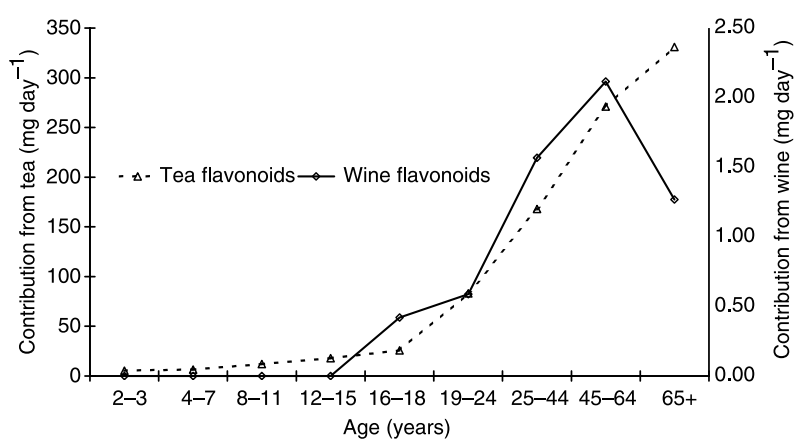

Fig. 7 Contribution to total flavonoid intake $\left(\mathrm{mg} \mathrm{day}^{-1}\right)$ of tea (left axis) and wine (right axis), according to age group; 24-hour recall data from the Australian National Nutrition Survey 1995 


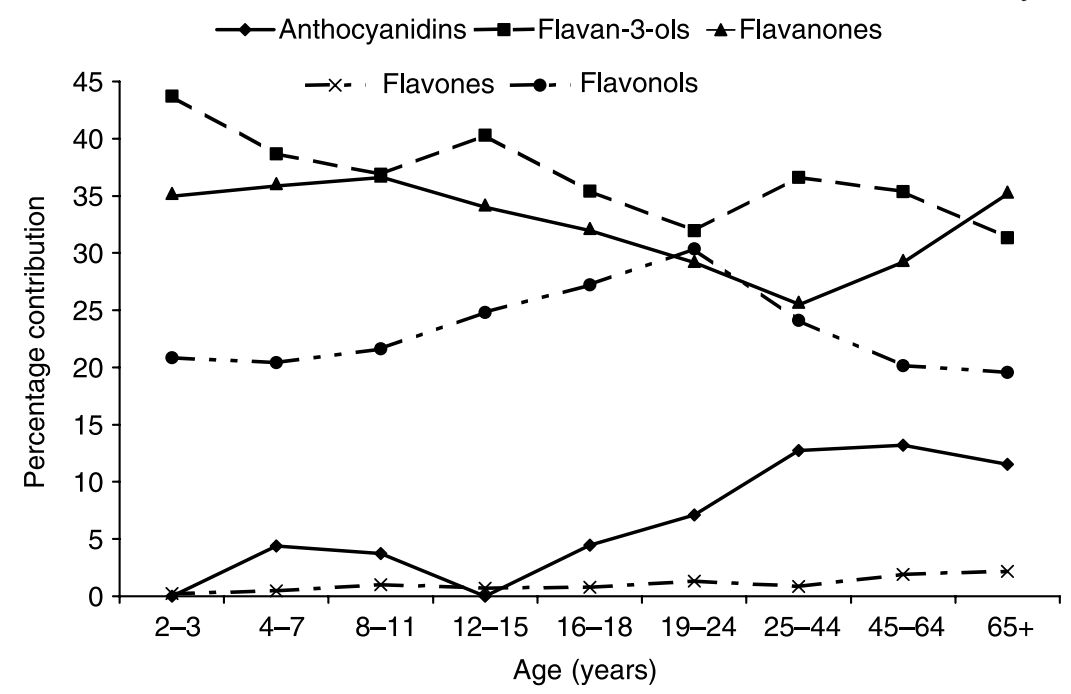

Fig. 8 Percentage of total flavonoid intake contributed by flavonoid classes, according to age (excluding tea consumption); 24-hour recall data from the Australian National Nutrition Survey 1995

dominated by 59\% attributed to flavon-3-ols. However, their study was based on only 15 flavonoids (vs. 26 in the present study). An analysis of our data using the same flavonoids as Lyons-Wall et al. ${ }^{30}$ (except for fisetin which is not included in the USDA database) yielded an average intake of $216 \mathrm{mg} \mathrm{day}^{-1}$ for people aged 19 years and over and $173 \mathrm{mg} \mathrm{day}^{-1}$ for 25-44-year-olds. Proportions of flavanones (3\%) and flavonols (10\%) in the present study were lower than those reported by Lyons-Wall et al. ${ }^{30}$ (18 and 20\%, respectively). Details of such studies from other countries are noted in Table 2.

Total flavonoid intake derived from apparent consumption data exceeded estimates from 24-hour recall data of a representative sample of the national population. This difference was despite the common occurrence of overreporting of flavonoid-rich foods (i.e. fruits and vegetables) reported previously in such surveys (NNS). Both apparent consumption and 24-recall data indicated that apigenin intake was markedly higher in Australia than reported in either the USA or Denmark, due presumably to differences in consumption of leaf and stalk vegetables (e.g. lettuce and celery) and parsley. Compared with the NNS95 analysis, apparent flavanone consumption was higher and apparent flavonol consumption lower due to differences in the ratio of orange to apple consumption in the two methods. The inherent weaknesses of apparent consumption estimates are well documented, and these data were included specifically as a comparison to previous studies which have used this same methodology.

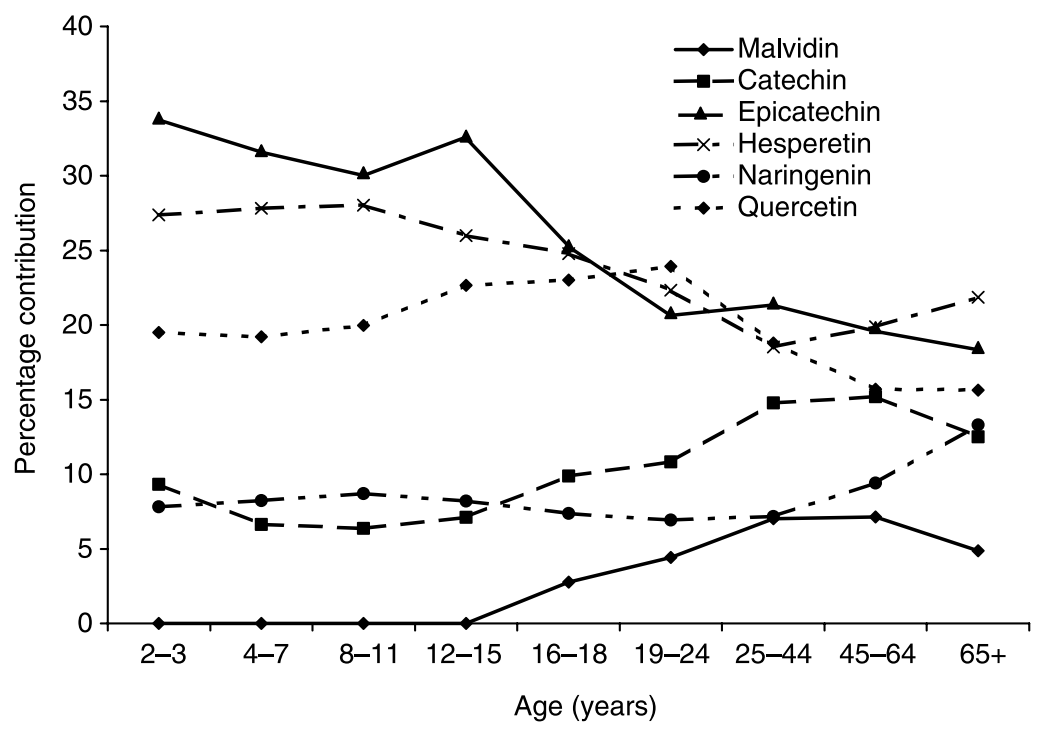

Fig. 9 Intake of major flavonoids, as a percentage of total flavonoid intake, according to age (excluding tea consumption); 24-hour recall data from the Australian National Nutrition Survey 1995 


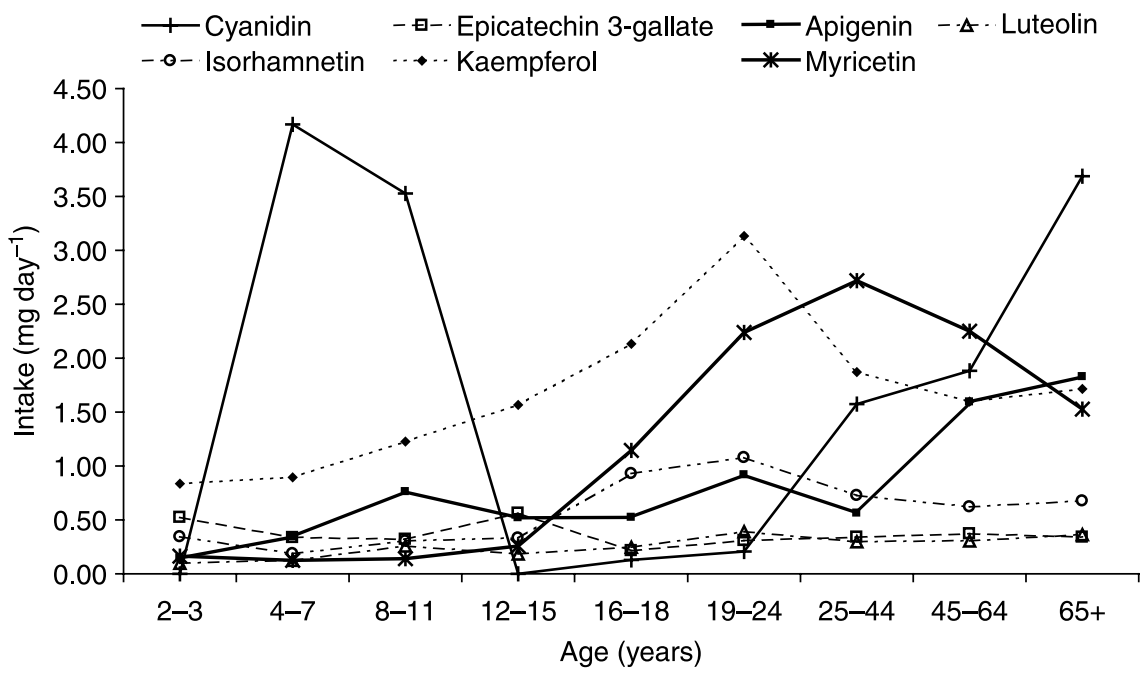

Fig. 10 Intake of minor flavonoids (mg day ${ }^{-1}$ ), according to age group (excluding tea consumption); 24-hour recall data from the Australian National Nutrition Survey 1995

If tea consumption is excluded for all ages, five flavonoids emerge as major dietary contributors: catechin, epicatechin, hesperetin, naringenin and quercetin. Even if their proportions of total flavonoid intake decrease with age, absolute intakes either remain constant or increase (except for young adults because of lower vegetable and fruit consumption). This study identifies apple consumption as an important flavonoid source for young people, as is citrus fruit for hesperetin and naringenin consumption. Hesperitin and naringenin have possible antiviral and antibacterial properties ${ }^{14}$ and anthocyanidins have been shown to exert effects on red blood cells ${ }^{15}$. It is therefore conceivable that variations in intake according to age may have some potential for impact on disease patterns.

Black tea and green tea differ in their flavonoid profiles. Green tea is richer in epicatechin, epicatechin-3-gallate, epigallocatechin and epigallocatechin-3-gallate (EGCG) but has lower levels of thearubigins and theaflavins ${ }^{28}$. Upwards of $78 \%$ of all tea consumption in Western countries is black tea, the contrary being true for Asian countries $^{33}$. Such variations may have health implications in view of the specific roles of the various flavonoids. For example, both thearubigins and EGCG are implicated in cancer prevention ${ }^{33,34}$ but EGCG is further implicated in heart disease aetiology $y^{32}$.

\section{Conclusion}

Estimates of total flavonoid consumption such as in the present study represent a preliminary step in the understanding of flavonoid-health relationships. At present, it is unclear whether absolute intakes of individual flavonoids or ratios between them are more relevant to human health. For this reason, intake studies should report data in both formats. Similarly, because of uncertainty regarding the chemical classification $^{35}$ and biological nature ${ }^{2}$ of flavonoids, data on individual flavonoids should be presented where possible. Food preparation methods are also an issue to be addressed in further studies, since there is clear evidence that these can affect bioavailability substantially ${ }^{28,36,37}$.

The present study reports age-related variations in the intake and sources of dietary flavonoids. Cohort studies are needed to determine if these variations are a longitudinal phenomenon. The profile of flavonoid intake seen in Australia from this present study revealed some differences to estimates from other countries. More consistent methods between studies are required to confirm the nature and extent of these differences.

\section{References}

1 Bruce W, Folkerts O, Garnaat C, Crasta O, Roth B, Bowen B. Expression profiling of the maize flavonoid pathway genes controlled by estradiol-inducible transcription factors CRC and P. Plant Cell 2000; 12(1): 65-79.

2 Scalbert A, Morand C, Manach C, Remesy C. Absorption and metabolism of polyphenols in the gut and impact on health. Biomedicine \& Pharmacotherapy 2002; 56(6): 276-82.

3 Ross JA, Kasum CM. Dietary flavonoids: bioavailability, metabolic effects, and safety. Annual Review of Nutrition 2002; 22: 19-34.

4 Hu FB, Willett WC. Optimal diets for prevention of coronary heart disease. Journal of the American Medical Association 2002; 288(20): 2569-78.

5 Cook NC, Samman S. Flavonoids - chemistry, metabolism, cardioprotective effects and dietary sources. Journal of Nutritional Biochemistry 1996; 7(2): 66-76.

6 Hollman PCH, Katan MB. Absorption, metabolism and health effects of dietary flavonoids in man. Biomedicine $\mathcal{E}$ Pharmacotherapy 1997; 51(8): 305-10.

7 Maron MD. Flavonoids for reduction of atherosclerotic risk. Current Atherosclerosis Reports 2004; 6(1): 73-8.

8 De Whalley CV, Rankin SM, Hoult JR, Jessup W, Leake DS. Flavonoids inhibit the oxidative modification of low density lipoproteins by macrophages. Biochemical Pharmacology 1990; 39(11): 1743-9. 
9 Negre-Salvayre A, Salvayre R. Quercetin prevents the cytotoxicity of oxidized LDL on lymphoid cell lines. Free Radical Biology \& Medicine 1992; 12(2): 101-6.

10 Steinberg D, Parthasarathy S, Carew TE, Khoo JC, Witztum JL. Beyond cholesterol. Modifications of low-density lipoprotein that increase its atherogenicity. New England Journal of Medicine 1989; 320(14): 915-24.

11 Laughton MJ, Evans PJ, Moroney MA, Hoult JR, Halliwell B. Inhibition of mammalian 5-lipoxygenase and cyclooxygenase by flavonoids and phenolic dietary additives. Relationship to antioxidant activity and to iron ironreducing ability. Biochemical Pharmacology 1991; 42(9): 1673-81.

12 Rolfes SR, Whitney EN, DeBruyne LK. Life Span Nutrition: Conception Through Life. Belmont, CA: Wadsworth, 1998.

13 Sizer F, Whitney E. Nutrition: Concepts and Controversies. Stamford, CA: Wadsworth, 2003.

14 Hanasaki Y, Ogawa S, Fukui S. The correlation between active oxygens scavenging and antioxidative effects of flavonoids. Free Radical Biology \& Medicine 1994; 16(6): 845-50.

15 Youdim KA, Shukitt Hale B, MacKinnon S, Kalt W, Joseph JA. Polyphenolics enhance red blood cells resistance to oxidative stress: in vitro and in vivo. Biochimica et Biophysica Acta 2000; 1519(1): 117-22.

16 Hope WC, Welton AF, Fiedler-Nagy C, Batula-Bernardo C, Coffey JW. In vitro inhibition of the biosynthesis of slow reacting substances of anaphylaxis (SRS-A) and lipoxygenase activity of quercetin. Biochemical Pharmacology 1983; 32(2): 367-71.

17 Kuhnau J. The flavonoids. A class of semi-essential food components: their role in human nutrition. World Review of Nutrition and Dietetics 1976; 24: 117-91.

18 Sampson L, Rimm E, Hollman PC, de Vries JH, Katan MB. Flavonol and flavone intake in US health professionals. Journal of the American Dietetic Association 2002; 102(10): 1414-20.

19 Justesen U, Knuthsen P, Leth T. Determination of plant polyphenols in Danish foodstuffs by HPLC-UV and LC-MS detection. Cancer Letters 1997; 114(1-2): 165-7.

20 Hertog MGL, Hollman PC, Katan MB, Kromhout D. Intake of potentially anticarcinogenic flavonoids and their determinants in adults in The Netherlands. Nutrition and Cancer 1993; 20(1): 21-9.

21 Kumpulainen JT. Intake of flavonoids, phenolic acids and lignans in various populations. In: Voutilainen S, Salonen JT, eds. Proceedings of Third International Conference on Natural Antioxidants and Anticarcinogenic Food, Health and Disease (NADH), 6-9 June 2001, Helsinki, Finland. Helsinki: Kuopion Yliopisto, 2001; 24.

22 Commenges D, Scotet V, Renaud S, Jacqmin-Gadda H, Barberger-Gateau P, Dartigues JF. Intake of flavonoids and risk of dementia. European Journal of Epidemiology 2000; 16(4): 357-63.
23 Lagiou P, Samoli E, Lagiou A, Peterson J, Tzonou A, Dwyer J, et al. Flavonoids, vitamin $\mathrm{C}$ and adenocarcinoma of the stomach. Cancer Causes \& Control 2004; 15(1): 67-72.

24 Arai Y, Watanabe S, Kimira M, Shimoi K, Mochizuki R, Kinae N. Dietary intakes of flavonoids, flavones and isoflavones by Japanese women and the inverse correlation between quercetin intake and plasma LDL cholesterol concentration. Journal of Nutrition 2000; 130(9): 2243-50.

25 Garcia-Closas R, Gonzalez CA, Agudo A, Riboli E. Intake of specific carotenoids and flavonoids and the risk of gastric cancer in Spain. Cancer Causes \& Control 1999; 10(1): 71-5.

26 Australian Bureau of Statistics (ABS). National Nutrition Survey 1995 (NNS95). Confidential Unit Record File (CURF). Canberra: ABS, 2001.

27 Australian Bureau of Agriculture and Resource Economics. Australian Food Statistics 2003. Canberra: Department of Agriculture, Fisheries and Forestry Australia, 2003.

28 US Department of Agriculture (USDA). USDA Database for the Flavonoid Content of Selected Foods. Washington, DC: USDA, Agricultural Research Service, 2003.

29 Arts ICW, Hollman PCH, Feskens EJM, Bueno de Mesquita $\mathrm{HB}$, Kromhout D. Catechin intake might explain the inverse relation between tea consumption and ischemic heart disease: the Zutphen Elderly Study. American Journal of Clinical Nutrition 2001; 74(2): 227-32.

30 Lyons-Wall P, Autenzio P, Lee E, Moss R, Gie S, Samman S. Catechins are the major source of flavonoids in a group of Australian women. Asia Pacific Journal of Clinical Nutrition 2004; 13(Suppl): S72.

31 Knekt P, Kumpulainen J, Jarvinen R, Rissanen H, Heliovaara $\mathrm{M}$, Reunanen A, et al. Flavonoid intake and risk of chronic diseases. American Journal of Clinical Nutrition 2002; 76(3): 522-8.

32 Arts ICW, Hollman PCH, Feskens EJ, Bueno de Mesquita HB, Kromhout D. Catechin intake and associated dietary and lifestyle factors in a representative sample of Dutch men and women. European Journal of Clinical Nutrition 2001; 55(2): $76-81$.

33 Siddiqui IA, Afaq F, Adhami VM, Ahmad N, Mukhtar H. Antioxidants of the beverage tea in promotion of human health. Antioxidants \& Redox Signaling 2004; 6(3): 571-82.

34 Lambert JD, Yang CS. Mechanisms of cancer prevention by tea constituents. Journal of Nutrition 2003; 133(10): 3262S-7S.

35 Haslam E. Thoughts on thearubigins. Phytochemistry 2003; 64(1): 61-73.

36 Andlauer W, Stumpf C, Hubert M, Rings A, Furst P. Influence of cooking process on phenolic marker compounds of vegetables. International Journal for Vitamin and Nutrition Research 2003; 73(2): 152-9.

37 Manach C, Scalbert A, Morand C, Remesy C, Jimenez L. Polyphenols: food sources and bioavailability. American Journal of Clinical Nutrition 2004; 79(5): 727-47. 